\title{
Study on Strategies for Methane Injection in a DISI (Direct Injection Spark Ignition) Engine
}

\author{
Fernanda P. Martins ${ }^{1}$, Francisco J. de Souza ${ }^{2}$, Pedro T. Lacava ${ }^{1}$ and Cláudia Regina de Andrade ${ }^{1}$ \\ 1. Aeronautical Technology Institute, São José dos Campos SP12228-900, Brazil \\ 2. Federal University of Uberlândia, UFU, Uberlândia SP38408-100, Brazil
}

Received: July 30, 2013 / Accepted: September 02, 2013 / Published: February 28, 2014.

\begin{abstract}
This paper deals with the application of two different injection strategies in a natural gas direct injection spark ignition single-cylinder engine model. The analysis includes the air flow characterization during compression stroke and also the charge stratification. Two different swirl ratios are applied and piston bowl effects are analyzed during the gas jet deflection towards the spark plug. Achieving wall-guided effect, consequently, the charge stratification in spark plug region is obtained. The goal is to study the mixture formation differences for a single and a bi pulsed CNG (compressed natural gas) injection profiles and check the evolution of the methane concentration at the spark plug at the start of combustion.
\end{abstract}

Key words: DISI (direct injection spark ignition), methane, injection profile.

\section{Definitions and Abbreviations}

BDC-Bottom dead center

$\mathrm{CAD}$ —Crank angle degree

CI-Compression ignition

DISI—Direct injection spark ignition

GDI-Gasoline direct injection

PFI-Port fuel injection

SI-Spark ignition

TDC— Top dead center

\section{Introduction}

One of the most promising fuels arisen in the last years in the alternative fuels scenario is the CNG (compressed natural gas) [1]. Over the last decade, engines operating with natural gas have shown their potential to meet the new emissions regulations. These engines can operate in different air-fuel ratios, but the lean mixture is the most largely applied. For each air-fuel ratio, different results for the combustion and pollutant emissions are obtained.

Corresponding author: Fernanda P. Martins, CFD analyst, research fields: computational fluid dynamics applied to internal combustion engines, alternative fuels. E-mail: fernanda.martins@gm.com.
Natural gas, as a compressible fuel, has a particular response to pressure differences between the injector and the chamber when compared to liquid fuels [2]. When analyzing diesel oil and gas behavior under the same pressure conditions, the gas tends to have a longer self-ignition delay, and a lower laminar flame speed.

The application of natural gas in engines is a very efficient option due to the combination of the emissions reduction and the fuel economy. Because of its lower adiabatic flame temperature, natural gas has a very low NOx formation index. Moreover, the gas has a very simple chemical structure (90\% to $98 \%$ methane) which leads to low particulate and HC formation [3].

\section{Objectives}

The main purpose of this paper is to investigate the behavior of natural gas under different injection strategies. A computational model representing a natural gas DISI (direct injection engine) is analyzed. The air flow pattern and the mixture formation during the compression stroke are studied. The wall guided combustion system effects on the in-cylinder charge 
stratification are considered for the flow characterization. Bowl geometry is proposed in order to guarantee the gas jet deflection towards the spark plug and a stoichiometric or rich equivalence ratio formation in this region.

The commercial codes ES-ICE and STAR-CD are used for moving meshes generation and solution of the conservation equations, respectively. The STAR-CD GUI is employed for post processing the results.

\section{DISI Engines}

Direct injection spark ignition engines represent the combination of the best characteristics of the compression ignition engines (Diesel) and the spark ignition engines (Otto) [4].

According to Ohm [5], the mixture preparation process and the combustion characteristics of this type of engine, when operating with gasoline, present fewer tendencies to knocking when compared to conventional PFI (port fuel injection) SI (spark ignition) engines. This fact suggests the possibility of working in higher compression ratios in DI engines. It is also observed that the volumetric efficiency of a GDI engine is higher than that of a PFI engine, due to the fuel evaporation, which is faster and more efficient in the direct injection engine.

Comparing the direct and indirect injections, and considering the cold start situation, the reduction of the HC emissions is observed in the former. This is a result of the stoichiometric operation in the direct injection instead of the rich equivalence ratio, normally used in PFI engines. [6]

\section{Stratified Charge}

According to Zhao et al. [7], the direct injection systems designed to operate in stratified charge can be classified as: spray-guided, wall-guided and air-guided. The specific nomenclature depends on the spray dynamics; the spray incidence on the piston surface and the mixture flow, respectively. It is important to mention that in an actual operation, all these systems contribute to charge stratification, but normally one of them predominates. A complementary description for these systems is given in Ref. [8]. According to those authors, the greatest challenge in stratified operation consists in the mixture formation optimization, which can be achieved in different ways: guided by spray, where the injector is positioned in such a way that the fuel jet is guided towards the spark plug; guided by tumble, where the in-cylinder charge motion is used to fuel deflection and also for mixture preparation; guided by swirl, where the charge motion is applied to the mixture formation. It is common to apply piston bowls in order to deflect the fuel.

The majority of DISI engines apply the wall-guided system to achieve charge stratification. This system consists in assembling the injector laterally in the cylinder and applying a piston with a deep bowl $[9,10]$.

In this system, during the stratified charge operation, the fuel is injected directly into the bowl and deflected towards the spark plug. The equivalence ratio near the spark plug must be sufficiently rich to guarantee the ignition and to reduce the misfire occurrence [5]. The predictability of the stratification effects is directly connected to the knowledge of the fuel behavior during the intake stroke. Factors such as: The intake air portion where this fuel is concentrated, how the air flow affects the fuel displacement and the fuel concentration near the spark plug at the ignition timing are very important [11-13].

\section{Numerical Methodology}

The Navier-Stokes Equations (continuity and momentum conservation) are solved using the commercial code STAR-CD [14]. Applying index notation they can be written as:

$$
\begin{gathered}
\frac{\partial \rho}{\partial t}+\frac{\partial\left(\rho \cdot \boldsymbol{u}_{j}\right)}{\partial x}=\boldsymbol{S}_{m} \\
\frac{\partial\left(\rho \cdot \boldsymbol{u}_{i}\right)}{\partial t}+\frac{\partial}{\partial \boldsymbol{X}_{j}}\left(\rho \cdot \boldsymbol{u}_{j} \cdot \boldsymbol{U}_{i}-\tau_{i j}\right)=-\frac{\partial p}{\partial \boldsymbol{X}_{j}}+\boldsymbol{S}_{i}
\end{gathered}
$$

where, $u$ corresponds to the fluid velocity vector; $u_{i}$ to 
the absolute component of the fluid velocity in the $x_{i}$ direction; $u_{j}$ is the velocity normal to the face of the cell; $s_{m}$ is the mass source term; $x_{i}$ are the Cartesian coordinates $(i=1,2,3)$; $\tau_{i j}$ are the tension tensor components and $s_{i}$ are the components from the momentum source term.

\section{Procedure and Geometry}

The main purpose of this investigation is to analyze the effect of two different injection strategies considering the stratification effects $[15,16]$. The bowl (Fig. 1) applied in this study is quite important to achieve the wall guided effect [9]. A section shows schematically the position for injector and spark plug. The spark plug was positioned in the center of the cylinder head, and the injector (represented by the dot line) was positioned 10 degrees inclined with relation to $\mathrm{Z}$ axis, in so that the gas jet initially impinges into one of the bowl sides.

The intake stroke was not considered in the calculations. The beginning of the simulation corresponds to the intake valve closing $40^{\circ}$ aBDC (after bottom dead centre) event, at which a swirl ratio is imposed as initial boundary condition. The combustion was not simulated, since the main objective of this work is to analyze the mixture formation in the spark plug. Thus, the results for the flammability limits are analyzed considering the mixture flow motion along the piston movement and its equivalence ratio at ignition timing (to be estimated).

It is important to mention that this simplified approach does not avoid the conclusions drawn in this work, since the flow characteristics during the compression are mainly dictated by the bowl geometry. Typically, the flow characteristics at the end of the intake stroke are due to the intake port geometry. So, assuming swirl motion as the initial condition of simulation corresponds to the utilization of a helicoidally or tangential intake ports.

The engine specifications are given in Table 1.

Because the interest lies in the concentration and
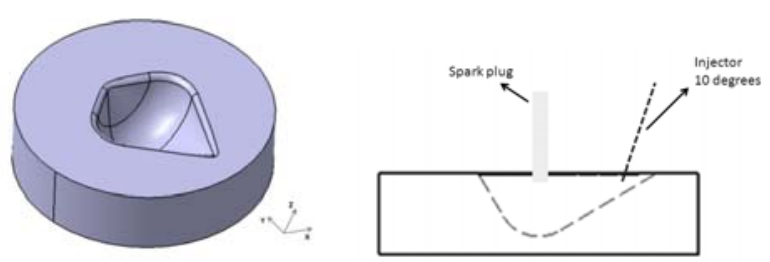

Fig. 1 Bowl geometry and injection model adopted.

Table 1 Cylinder specifications.

\begin{tabular}{ll}
\hline Parameter & Dimension \\
\hline Stroke & $160 \mathrm{~mm}$ \\
Displacement volume & $2,133.17 \mathrm{~cm}^{3}$ \\
Diameter & $128 \mathrm{~mm}$ \\
Bowl volume & $74.36 \mathrm{~cm}^{3}$ \\
Speed & $1,800 \mathrm{rpm}$ \\
Rod length & $215 \mathrm{~mm}$ \\
Compression ratio & $14: 1$ \\
\hline
\end{tabular}

flow pattern evolution up to the ignition, only the compression stroke is simulated after the intake valves closing, during a 180 CAD interval, starting at 220 CAD. The coherence of the results obtained from the simulations is directly dependent on the mesh resolution. The mesh resolutions used in this work corresponded to 331,000 cells at BDC and 28, 800 cells at TDC.

\section{Injection Strategies and Initial Conditions}

The initial conditions for the intake air are 1 bar for pressure and $298 \mathrm{~K}$ for temperature

As boundary conditions for the cylinder head it was imposed a temperature equivalent to $450 \mathrm{~K}$, and for cylinder walls and piston crown was assumed $370 \mathrm{~K}$ and $500 \mathrm{~K}$, respectively.

The swirl ratios and the injection profiles considered are presented in Table 2.

In his work, Cheng [12] presents that a $1 \mathrm{~ms}$ injection duration represents a 1 ms delay in the ignition. From injection durations longer than $2 \mathrm{~ms}$, the delay is constant and equivalent to $1.7 \mathrm{~ms}$.

Based on this information, the injection profile referent two a two-pulse injection profile (Table 3) was proposed, with two $1 \mathrm{~ms}$ pulses and an interval of $1 \mathrm{~ms}$ between them. The injection velocity was equivalent to $218 \mathrm{~m} / \mathrm{s}$. 
Table 2 Configurations of the analysis performed.

\begin{tabular}{lll}
\hline Case & Swirl ratio & Injection strategy \\
\hline Case 1 & 1.0 & Two pulses \\
Case 2 & 1.0 & One pulse \\
Case 3 & 2.5 & Two pulses \\
Case 4 & 2.5 & One pulse \\
\hline
\end{tabular}

Table 3 Injection timing for cases 1 and 3.

\begin{tabular}{ll}
\hline Event & Time of occurrence \\
\hline Start of first pulse of injection & 320 CAD \\
Duration of first pulse of injection & 10.8 CAD (1 ms) \\
Start of second pulse of injection & 341.6 CAD aTDC \\
Duration of second pulse of injection & 10.8 CAD $(1 \mathrm{~ms})$ \\
\hline
\end{tabular}

Table 4 Injection timing for cases 2 and 4.

\begin{tabular}{ll}
\hline Event & Time of occurrence \\
\hline Start of injection & 335.0 CAD \\
End of injection & 345.6 CAD \\
\hline
\end{tabular}

\section{Results}

The main parameter considered in this analysis was the mixture formation behavior considering two different injection profiles. In cases 1 and 3 , a big-pulsed injection was applied, and in cases 2 and 4 (Table 4), a single pulse injection was studied. The stratification effect was achieved applying piston bowl geometry and feasible configuration for spark plug and injection position.

\subsection{Swirl and Tumble}

This analysis considered imposed swirl ratios, as long as the analysis just considered 200 crank angle degrees and the valves were closed. It was assumed that this swirl ratio imposed could be resultant by special intake port geometry or by other mechanism.

Analyzing Figs. 2 and 3, it can be seen that at the beginning of compression stroke, the swirl structure is maintained for all the cases. Nevertheless, after 60 CAD bTDC (before top dead center)—As the compression stroke advances, there is a substantially decrease in the swirl ratios caused by the start of injection.

This effect is more pronounced for cases 2 and 4, which swirl ratio is equal to 2.5 .

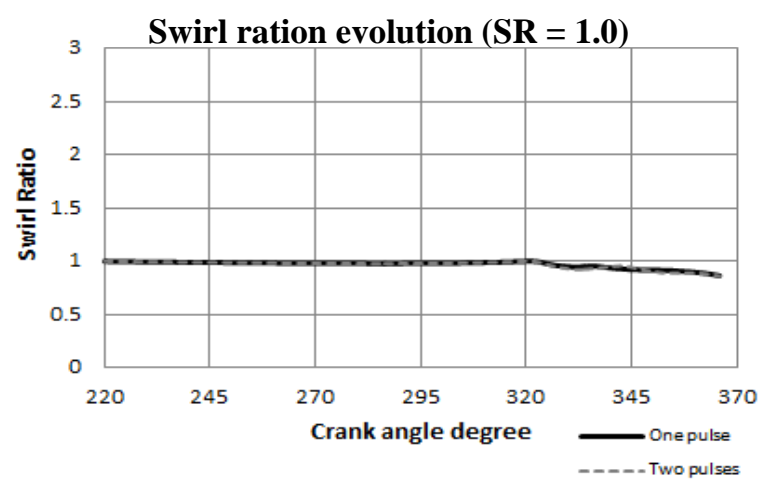

Fig. 2 Swirl ratios evolution, swirl ratio $=\mathbf{1 . 0}$.

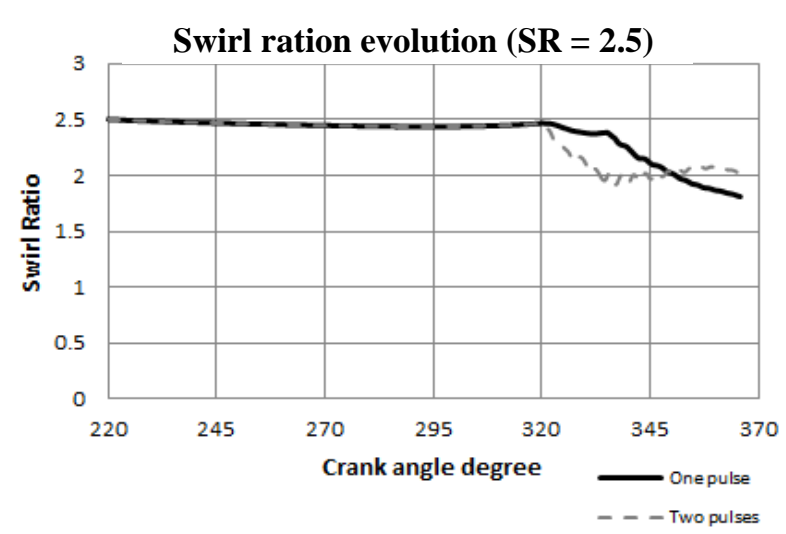

Fig. 3 Swirl ratios evolution swirl ratio $=2.5$.

As the gas is injected into combustion chamber, there is momentum transferred by the fuel jet causing the breakdown of swirl motion into less organized flow structures. At same time, new flow motions appear, such as the squish (the transversal motion of the charge towards the piston bowl), as the piston approaches the TDC.

Besides the two injection pulses, other causes for the swirl motion breakdown and its consequent dissipation into turbulent kinetic energy are the approximation of the piston to the TDC. At this moment, the influence of the bowl shape on the flow motion is more significant, indicating that the geometry simulated leads to large vortex dissipation and the consequent increases in turbulent kinetic energy. Moreover, it can be concluded that there is more dissipation in the momentum for the cases where the highest swirl ratio was applied. Thus, it can be concluded that the piston bowl tends to destroy the swirl movement when flows with higher swirl ratios are employed. 


\subsection{Turbulent Kinetic Energy}

The evolution of the turbulent velocity, which corresponds to the square root of the turbulent kinetic energy, can be observed in Figs. 4 and 5 for the four cases studied.

Fig. 2 presents the cases 1 and 3-Swirl ratio equal to 1.0 . For case 1 the turbulent velocity increases at two different points (320 CAD and 342 CAD), both related to the beginning of the first and second injection, respectively. For case 2, there is an increasing in turbulent velocity around $335 \mathrm{CAD}$, connected to the beginning of the one single pulse injection.

On the other hand, analyzing the Fig. 4-Regarding cases 3 (two pulses) and 4 (single pulse), for both cases only one peak of turbulent velocity can be observed. In the two pulses injection probably the second pulse momentum is not sufficient to increase the turbulent velocity, and also provides the charge stratification effect desired. Moreover, for case 4 the peak is lower than case 3, which indicates that probably the start of injection needs to be delayed in order to occur closer to TDC, achieving higher turbulent velocity values.

The increases of the energy in all the cases result from the conversion of the swirl movement into turbulent kinetic energy, in other words, the vortex breakdown and the dissipation of energy.

For cases 1 and 3, the pronounced increase of turbulent kinetic energy after the first pulse is directly connected to two factors: the start of injection and the bowl geometry, because the results show that this leads to the swirl breakdown into small vortices, dissipating energy. The irrelevant increase of the energy after the second pulse is a consequence of two factors: the high dissipation that occurs after the first pulse and also the small momentum of the gas jet after the second pulse.

For cases 2 and 4, two peaks are observed where energy amounts are lower than for the other two cases.

The desired results for all the four cases would be the mixture homogenization after the first pulse and the maintenance of the swirl motion. The swirl movement breakdown should occur after the second pulse in the

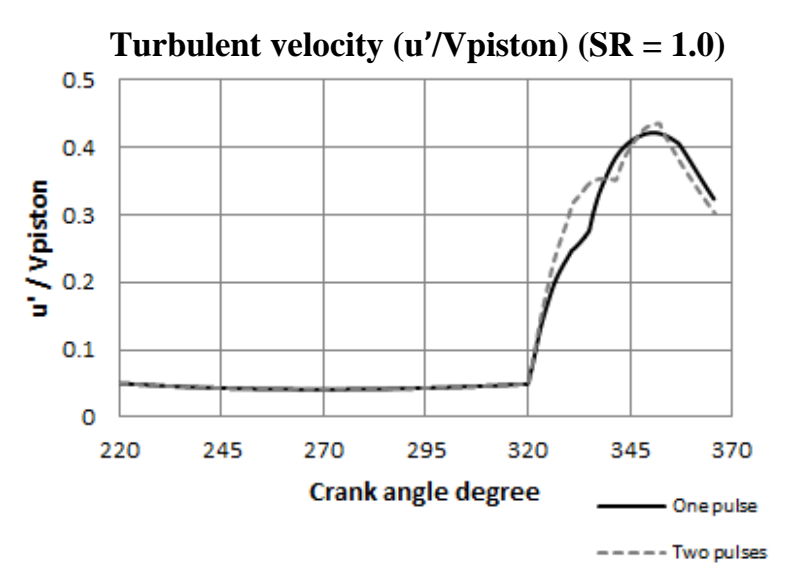

Fig. 4 Average turbulent velocity, normalized by the average piston speed $($ vpiston $=16 \mathrm{~m} / \mathrm{s}$ ), $\operatorname{sirl}$ ratio $=\mathbf{1 . 0}$.

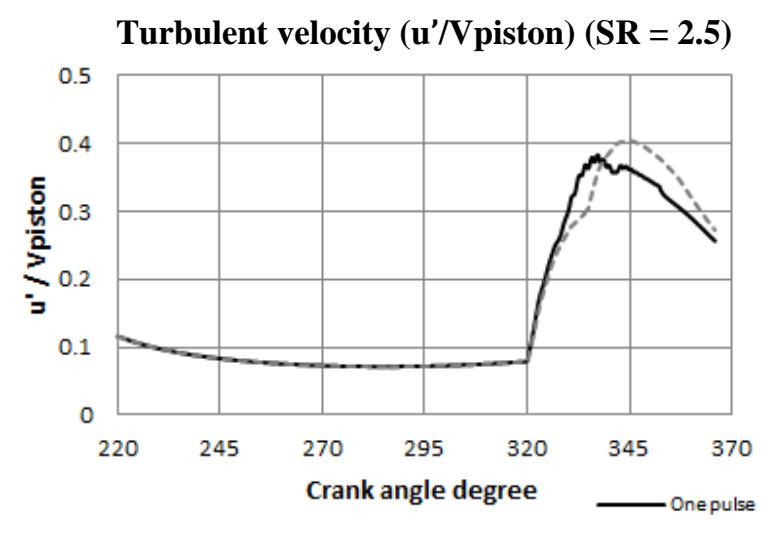

Fig. 5 Average turbulent velocity, normalized by the average piston speed $($ vpiston $=16 \mathrm{~m} / \mathrm{s})$, $\operatorname{sirl}$ ratio $=2.5$.

cases where the bi-pulsed injection was applied, so in a moment closer to the ignition timing. This would accelerate the mixture combustion velocity.

One possible solution to guaranteeing an adequate development for the second injection would consist in increasing the gas jet velocity for the second pulse; this would lead to an increase in the momentum.

Figs. 6 and 7 present the distribution for dissipation energy. It can be seen that for the cases where a two pulse injection was applied there is a more pronounced dissipation for both swirl ratios.

\subsection{Mixture Formation}

A centered spark plug $(0,0, \mathrm{Z})$ was deliberately used so that, based on the equivalence ratio distribution, the best position for the spark plug with relation to $\mathrm{Z}$ axis 


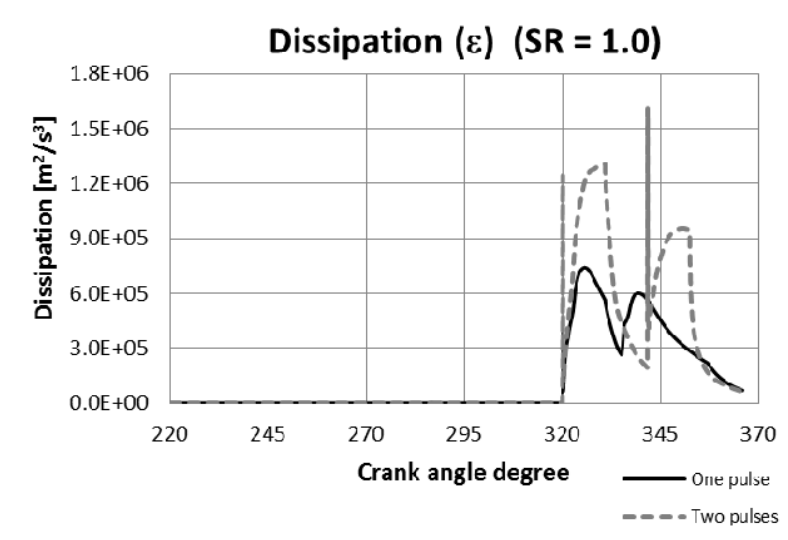

Fig. 6 Dissipation, swirl ratio $=\mathbf{1 . 0}$.

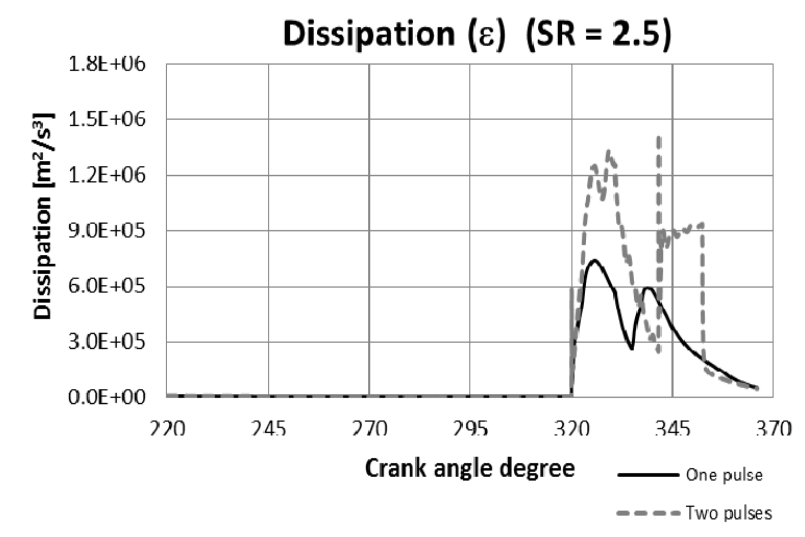

Fig. 7 Dissipation, swirl ratio $=2.5$.

can be inferred. It was analyzed that the equivalence ratio in ten previously defined monitored position, located along the $\mathrm{Z}$ axis centered on combustion chamber.

The results related to the mixture formation are evaluated considering many criteria based on the mixture formation characteristics, as well as in the ignition conditions at the spark plug. The equivalence ratio in the region near the spark plug will be used in order to determine the start of ignition, indicating also if the stratified charge operation was achieved. The flammability limits available in Ref. [17] are applied. For pure methane combustion these values are 0.53 and 1.60 for lean and rich limits, respectively.

Figs. 8-11 present the equivalence ratio in the monitored positions for all the four cases studied.

The lower flammability limit was achieved in almost all the monitored positions, at different crank angle positions.

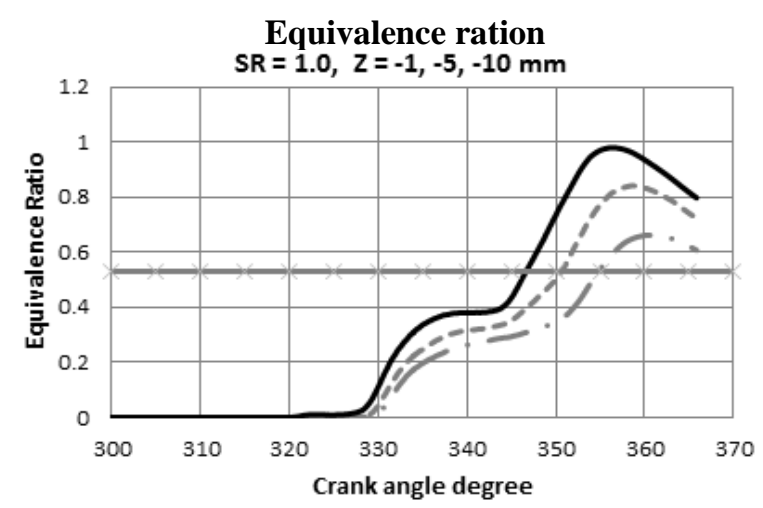

$-\mathrm{Z}=-1 \mathrm{~mm} \quad--\mathrm{z}=-5 \mathrm{~mm} \longrightarrow \mathrm{Z}=-10 \mathrm{~mm} \longrightarrow$ LIF Glassman

Fig. 8 Equivalence ratio in each monitored position, case 1: swirl ratio $=1.0$, two injection pulses.

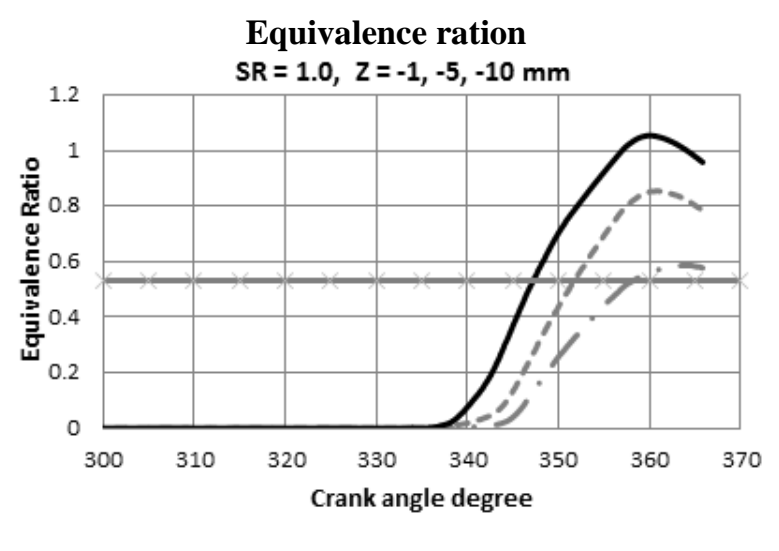

Fig. 9 Equivalence ratio in each monitored position, case 2: swirl ratio $=1.0$, single injection pulse.

For cases 1 and 2, whose swirl ratio is 1.0, the mixture achieves the flammability limit for all the positions, mainly in positions closer to cylinder head. Moreover, for the single injection profile (case 2) the mixture gets richer in more advanced crank angles positions than case 1 .

Figs. 10 and 11 show the contour plots obtained for both injection profiles considering the 2.5 swirl ratio. The plot regarding the one single pulse injection shows that this profile achieves higher equivalence ratio values for all the positions, so probably the combustion evolution by the ignition time will be more effective.

By comparing the plots for equivalence ratios considering the two distinct swirl ratios, it can be concluded that when the swirl ratio increases, the mixture tends to maintain lean in all the monitored 


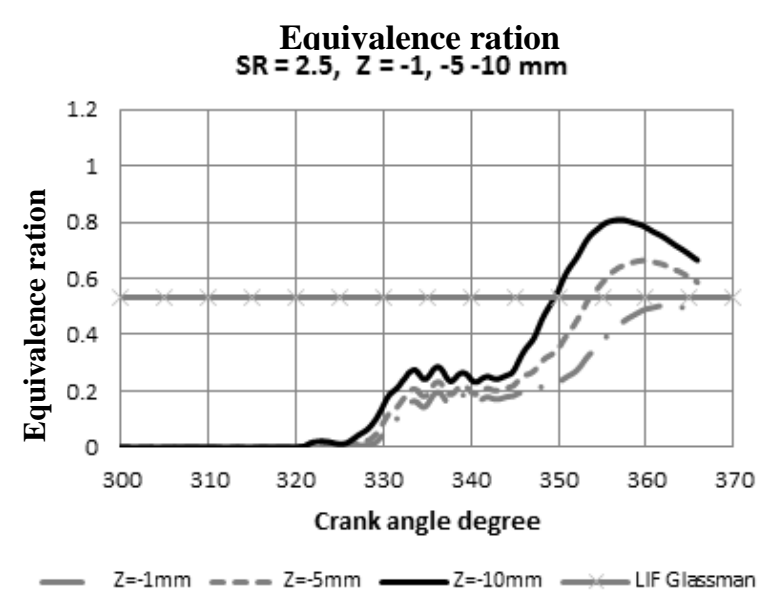

Fig. 10 Equivalence ratio in each monitored position, case 3 : swirl ratio $=2.5$, two injection pulses.

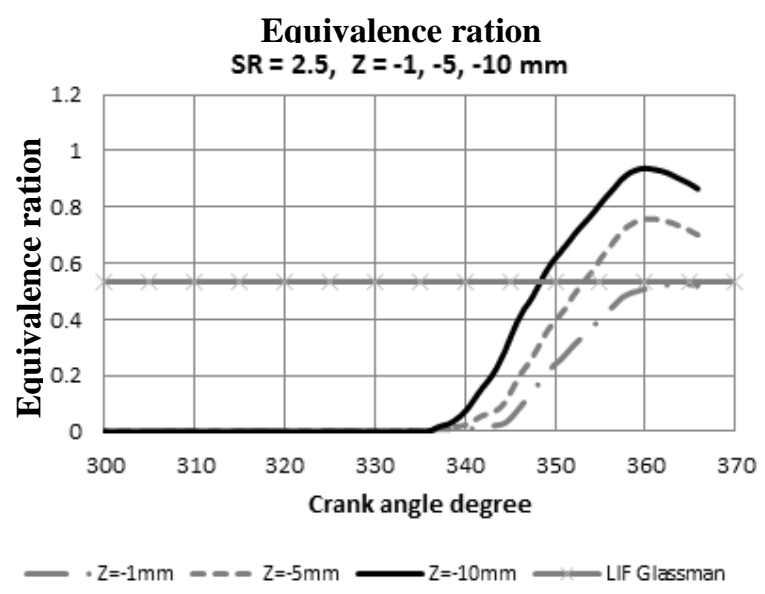

Fig. 11 Equivalence ratio in each monitored position, case 4: swirl ratio $=2.5$, single injection pulse.

positions. Case 3, for the position $Z=-1 \mathrm{~mm}$, did not achieve the LIF, indicating that if the spark plug were positioned in this place, the mixture might not ignite. A better combustion condition is achieved by case 4 in the same position, for this the equivalence ratio is equal to the LIF.

\section{Conclusions}

The charge movement, the chamber geometry and the gas jet development in a DI engine were investigated by means of the numerical simulation. Some important characteristics of the mixture formation are identified, such as the stratified charge behavior. The effect of bowl geometry in the methane jet is analyzed with the objective of obtaining the wall-guided effect.

Results for two different swirl ratios, demonstrate that they influence the distribution of the turbulent kinetic energy and the charge stratification in the cylinder. Moreover, two different injection profiles were analyzed in order to evaluate the best strategy for gas direct injection. The results obtained can be used as guidelines to estimate the best spark plug position and also the best ignition timing. Also, injection profile can be better evaluated. Nevertheless, this must be confirmed by other simulations.

It was confirmed by this research that Computational Fluid Dynamics provides a better understanding of the processes taking place in internal combustion engines and the interaction between them, such as the air flow and the fuel injection. It is also an important design tool as it allows the optimization of parameters such as bowl geometry and injection strategy applied. It can be said that numerical simulation can be used to improve concepts already available in the industry, aiming at more efficient and less pollutant engines.

\section{References}

[1] H.M. Cho, B. He, Spark ignition natural gas engines: A review, Energy Conversion and Management 48 (2) (2007) 608-618.

[2] G. Papageorkis, D.N. Asanis, Optimizing gaseous fuel air-mixing in direct injection using an RNG based k-e model, in: International Congress and Exposition, Detroit, Michigan, 1998.

[3] P. Oullette, Direct injection of natural gas for fueling engines, Ph.D. Thesis, University of British Columbia, Vancouver, 1996.

[4] C. Stan, Direct injection Systems: The Next Decade in Engine Technology, SAE International, Warrendale, 2002, p. 112.

[5] I.Y. Ohm, Y.S. Cho, Mechanism of axial stratification and its effect in an SI engine, in: SAE 2000 World Congress, Detroit, Michigan, 2000.

[6] J.B. Heywood, Internal Combustion Engine Fundamentals, McGraw-Hill, New York, 1988, p. 930.

[7] F. Zhao, D.L. Harrington, M. Lai, Automotive Gasoline Direct Injection Engines, SAE International, Warrendale, 2002, p. 356.

[8] P. Adomeit, B. Vogt, Computational analysis of flow and mixture formation in DISI engines, in: International 
Multidimensional Engine Modeling User’s Group Meeting, Detroit, Michigan, 2002.

[9] R. Diwakar, S. Singh, Importance of spray-bowl interaction in a DI Diesel engine operating under PCCI combustion mode, in: SAE 2009 World Congress, Detroit, Michigan, 2009.

[10] E.C. Viana, F.J. Souza, M. Langeani, Effects of swirl motion on methane homogenous combustion in the AVL Triflow system, in: Congresso e Exposição Internacionais de Tecnologia da Mobilidade SAE Brasil São Paulo, Brasil, 2009.

[11] T.A. Kumar, J. M. Mallikarjuna, V. Ganesan, Effect of injection timing on fuel-air mixing and combustion in a direct injection stratified charge SI engine, in: Joint Rail Conference and Internal Combustion Engine Division Spring Technical Conference, Pueblo, New York, 2007.

[12] X. Cheng, Modeling injection and ignition in direct injection natural gas engines, Ph.D. Thesis, University of Toronto, Canada, 2008.

[13] A. A-Aziz, Firmansyah, The effect of fuel rail pressure on the performance of a CNG-direct injection engine, SAE Technical Paper 2009-01-1498, 2009.

[14] STAR-CD, Methodology: Manual Star-CD version 4.08, SI, 2000, p. 380.

[15] E.J. Gunasekaran, V. Ganesan, Mixture preparation strategies for a four valve centrally injected flat piston DISI engine, in: Joint Rail Conference and Internal Combustion Engine Division Spring Technical Conference, Pueblo, New York, 2007.

[16] H. Schapertons, F. Thiele, Three dimensional computations for flow fields in DI piston bowls, in: International Congress and Exposition, Detroit, Michigan, 1989.

[17] I. Glassman, Combustion, 2nd ed., Academic Press, Orlando, 1987, p. 524. 